\title{
CIÊNCIA DA INFORMAÇÃO, TECNOLOGIA E SOCIEDADE
}

\author{
RODRIGO HIPÓLITO ROZA*
}

\begin{abstract}
RESUMO
As Tecnologias da Informação e Comunicação (TICs) são responsáveis, em grande parte, pelas diversas transformações ocorridas na atual sociedade, denominada sociedade da informação por alguns autores. Essa importância atribuída às TICs pode, no entanto, levar a abordagens meramente tecnológicas para tratamento das questões informacionais atuais. O objetivo deste artigo é abordar a perspectiva da ciência da informação sobre as transformações sociais alicerçadas nos avanços tecnológicos. Assim, a ciência da informação é apresentada como área interdisciplinar de conhecimento, cujas dimensões humanas e sociais vão além das tecnologias, fornecendo uma visão mais ampla sobre a realidade baseada nos recursos tecnológicos, essencial para a compreensão e desenvolvimento da sociedade da informação.
\end{abstract}

PALAVRAS-CHAVE: ciência da informação, interdisciplinaridade, tecnologia da informação e comunicação, sociedade.

\begin{abstract}
Information and Communication Technologies (ICTs) are responsible, in large part, for the various transformations that have taken place in the current society, called the information society by some authors. This importance attributed to ICTs may, however, lead to purely technological approaches to address current informational issues. The objective of this article was to address the perspective of information science on social transformations based on technological advances. Thus, information science is presented as an interdisciplinary area of knowledge, whose human and social dimensions go beyond technologies, providing a broader view of reality based on technological resources, essential for the understanding and development of the information society.
\end{abstract}

KEYWORDS: information science, interdisciplinarity, information and communication technology, society.

\section{INTRODUÇÃO}

\author{
Muitas das transformações observadas na atual sociedade \\ devem-se aos avanços das denominadas Tecnologias da
}


Informação e Comunicação (TICs). Tais tecnologias abrangem um vasto conjunto de recursos destinados ao tratamento, à organização e à disseminação de informação (TAKAHASHI, 2000), sejam eles dispositivos de hardware ou software, simples aplicativos ou complexos sistemas de inteligência artificial. Elas modificam radicalmente a forma como o indivíduo e a sociedade como um todo lidam com a informação, abrindo novos horizontes no que se refere ao acesso e à aquisição de conhecimento.

As TICs estão associadas aos fenômenos de explosão da quantidade de informação e implosão do tempo, sendo este caracterizado pela redução drástica do tempo de disseminação da informação (LE COADIC, 1996). Se, por um lado, as TICs beneficiam a sociedade em sua relação com a informação; por outro, também contribuem com o surgimento de diversos problemas informacionais, como, por exemplo, a sobrecarga de informação ou ainda a falta de confiabilidade das informações produzidas e disseminadas.

Apesar da importância das TICs na sociedade, é importante salientar que as tecnologias não são as únicas responsáveis pelas transformações sociais. A nova forma de sociedade é, na realidade, fruto de diversas e profundas mudanças sociais, econômicas, culturais e, inclusive, tecnológicas ocorridas de forma conjunta (CASTELLS, 2010). Contudo, soluções meramente tecnológicas são adotadas com frequência em respostas às atuais questões informacionais, o que de fato é uma abordagem simplista e reducionista. Diante desse contexto, este artigo aborda a perspectiva da ciência da informação sobre as transformações sociais baseadas nos avanços tecnológicos.

\section{CIÊNCIA DA INFORMAÇÃO}

No campo da informação, as primeiras disciplinas foram a biblioteconomia, a museoconomia, a documentação e o jornalismo, conforme apontado por Le Coadic (1996). Observa-se que, neste caso, privilegiou-se o uso do termo museoconomia em relação ao termo museologia, como uma forma de remeter à "ciência" dos museus rumo a uma economia dos museus.

Ainda segundo o autor, tanto na biblioteconomia como na museoconomia existe um grande enfoque nos suportes da informação, que supera o interesse pela informação em si. Assim, as bibliotecas voltam-se aos livros, ao passo que os museus direcionam-se aos objetos, ambos com um propósito de 
preservação patrimonial. Já a documentação e o jornalismo têm a informação como objeto. No entanto, também atribuem bastante importância aos documentos e às mídias.

Todavia, a ciência da informação, diferentemente das disciplinas que a precederam no campo da informação, dedica-se ao estudo das propriedades gerais da informação (LE COADIC, 1996). Assim, busca analisar os processos de construção, comunicação e uso da informação, bem como conceber produtos e sistemas que possibilitam a construção, a comunicação, o armazenamento e o uso da informação. Os processos de construção, comunicação e uso da informação, em particular, estão ligados uns aos outros, alimentando-se de forma recíproca. Como resultado, tem-se o ciclo da informação, que representa o modelo social da comunicação.

O modelo social da informação é essencialmente diferente de outros modelos muito difundidos: o modelo de comunicação em massa e o modelo da teoria da informação. O primeiro restringe a comunicação à relação bilateral entre informador e informado. $O$ segundo, baseado na matemática e na física (SHANNON, 1948; SHANNON \& WEAVER, 1975), considera que, entre emissor e receptor, existe uma relação linear e que a comunicação se passa por meio da transmissão de uma mensagem.

Como uma forma de representar, de um lado, a geração de informação e, de outro lado, a absorção dessa informação no espaço dos receptores, Barreto (1999, p. 372) recorre, metaforicamente, às imagens do cristal e da chama:

O cristal com seu facetado preciso e sua capacidade de refratar a luz é a representação da invariância, da regularidade das estruturas, imagem que muito bem se adapta a geração de informação e é onde a Ciência da Informação tem se inspirado para a sua ideologia de centralidade do discurso do autor e a homogeneização das estruturas de inscrição de informação. Refletindo em muitas direções o cristal se transforma em chama que é a imagem da não constância de uma forma exterior e que associamos ao sujeito em sua incessante agitação interna de reflexão, cada indivíduo em sua individualidade; manipulando sua sensibilidade e percepção no trato com a informação.

Nesse sentido, o autor ressalta aspectos como produção e armazenamento de informação e diferenças relacionadas aos espaços sociais em que os receptores de informação se encontram e as características particulares desses indivíduos. A produção de informação envolve atividades de reunião, seleção, codificação, 
redução, classificação e armazenamento de informação, que se orientam à organização e ao controle de estoques de informação. Esses estoques são fontes potenciais de conhecimento e imprescindíveis para a transferência de informação. Contudo, são estáticos, não podendo por si só produzir conhecimento.

Já o armazenamento enfrenta o desafio de lidar com quantidades cada vez maiores de informação. Assim, deve ser realizado de modo eficiente, pautado por critérios de produtividade de estocagem, utilizando-se de técnicas de redução e reformatação de conteúdos. No entanto, os resultados do emprego de tais técnicas podem ser a redução semiótica do conteúdo e do potencial da informação. Nesse processo redutor, observa-se o uso de novas linguagens advindas dos instrumentos da ciência da informação.

Quanto aos espaços sociais, nota-se que eles são distintos. Além disso, os indivíduos que o compõem diferem, por exemplo, em aspectos como grau de instrução, renda, religião, raça, nível de acesso que têm à informação, confiança nos canais utilizados para transferência de informações e codificação e decodificação do código linguístico comum. Desse modo, Barreto (1999) complementa que os produtores de informação são limitados por competências contextuais e cognitivas dos indivíduos pertencentes a realidades distintas.

Ademais, tanto em relação ao produtor como ao receptor, a informação se mostra de forma ambivalente. Ela sempre passa pelo filtro da subjetividade e encontra limites na percepção e no aparato de contextualização dos indivíduos (DEMO, 2000). Assim, indivíduos com repertórios e experiências distintos podem compreender a mesma informação de formas diferentes.

De forma geral, a ciência da informação apresenta três características que mostram sua evolução e sua existência, compondo uma estrutura que permite compreender seu passado, presente e futuro, segundo Saracevic (1995). A primeira característica é sua natureza interdisciplinar. A segunda é sua forte ligação com a tecnologia da informação, que impulsiona a própria ciência da informação e a sociedade da informação. Por fim, a terceira é sua participação ativa na evolução da sociedade da informação, marcada por sua forte dimensão social humana e social, que prevalece sobre a tecnologia.

\section{INTERDISCIPLINARIDADE NA CIÊNCIA DA INFORMAÇÃO}

Dentre as várias áreas que se relacionam, de forma interdisciplinar, com a ciência da informação, as mais desenvolvidas 
e significativas, segundo Saracevic (1995), são a biblioteconomia, a ciência da computação, a ciência cognitiva e a comunicação. Já Le Coadic (1996) prefere destacar que a interdisciplinaridade na ciência da informação envolve, principalmente, as seguintes áreas: psicologia, linguística, informática, matemática, lógica, estatística, eletrônica, economia, direito, filosofia, política e telecomunicações.

Considerando, inicialmente, as explicações de Saracevic (1995), é possível destacar que a biblioteconomia, voltada à organização, à preservação e ao uso de registros, possui uma base comum com a ciência da informação em seu papel social e a atenção dada ao uso de registros de informação. Contudo, são áreas distintas, com abordagens diferentes de seleção ou definição de problemas, paradigmas, soluções práticas e referenciais teóricos.

A ciência da computação também possui uma relação próxima com a ciência da informação. Possivelmente, o aspecto mais marcante seja o emprego de recursos computacionais, como produtos, serviços e redes, na área de ciência da informação.

Com o propósito de explicar como a mente funciona, a ciência cognitiva preocupa-se em compreender os processos cognitivos do indivíduo, como esses processos se passam no cérebro, a estrutura da mente e as inúmeras manifestações da mente. A inteligência artificial e a interação humano-computador são dois campos explorados pela ciência cognitiva, que também despertam interesse da ciência da informação.

A comunicação, por sua vez, tem relacionamentos múltiplos com a ciência da informação. Essas duas áreas possuem confluência de algumas linhas de pesquisa, cooperação profissional e compartilham o interesse pela comunicação humana, por exemplo. Observa-se que o próprio relacionamento entre informação e comunicação é muito forte. A informação se mostra como um fenômeno e a comunicação como processo de transferência ou compartilhamento desse fenômeno.

Para os propósitos do presente estudo, duas áreas citadas por Le Coadic (1996) são especialmente importantes: a informática e as telecomunicações. É importante notar que ambas possuem interfaces com outras áreas citadas pelo autor, como a eletrônica, ou ainda a lógica e a matemática.

A informática, tradicionalmente, foi associada ao domínio da tecnologia da informação (TI), abrangendo os recursos tecnológicos voltados ao processamento e armazenamento de dados. Nesse sentido, inclui recursos como computadores (TANENBAUM, 2009), softwares de um modo geral (REZENDE, 2005; PRESSMAN, 2011), 
redes computacionais (SOARES, LEMOS, COLCHER, 1995; TANENBAUM, WETHERALL, 2011) e a Internet, cuja capacidade de transmissão atinge as mais remotas regiões do planeta, proporcionando mecanismos para disseminação de informação, colaboração e interação (LEINER et al., 2009).

As telecomunicações, como o próprio no diz, referem-se a comunicações a distância (DODD, 2000; WALDMAN; YACOUB, 1997). Contudo, não diz respeito à comunicação humana, mas sim às comunicações envolvendo a troca de sinais entre equipamentos através de meios de transmissão.

Além disso, com a evolução das tecnologias, a informática e as telecomunicações convergiram para uma base tecnológica comum. Dessa forma, a palavra comunicação foi acrescentada à expressão Tecnologia da Informação, TI, resultando em Tecnologia da Informação e Comunicação, TIC (STEVENSON COMMITTEE, 1997). O propósito deste acréscimo foi destacar a relevância tanto das tecnologias de informação como de comunicação na atual sociedade.

Considerando, ainda, os objetivos do presente estudo, mas com foco nas áreas apontadas por Saracevic (1995), é possível destacar a interdisciplinaridade da ciência da informação com a ciência da computação. Em linhas gerais, a ciência da computação trata sobre aspectos computacionais associados à informação, enquanto a ciência da informação aborda a natureza da informação e o uso da informação por humanos.

Embora muitos esforços de pesquisa e desenvolvimento conduzidos no âmbito da ciência da computação estejam desvinculados da ciência da informação, vários deles têm foco em problemas similares, como sistemas especialistas e bases de "conhecimento", big data (BEGOLI; HOREY, 2012; FALSARELLA, JANNUZZI, 2017) ou ainda interação humano-computador (BARANAUSKAS, SOUZA, PEREIRA, 2015; HEWETT et al., 1992) e inteligência artificial (RUSSELL; NORVIG, 2013), sendo estes dois últimos também abordados dentro do conjunto de interesses da ciência cognitiva.

\section{CIÊNCIA DA INFORMAÇÃO E AS TRANSFORMAÇÕES SOCIAIS BASEADAS EM TECNOLOGIA}

No final do século passado, mais precisamente durante a década de 90, a ciência da informação voltou-se tanto à investigação científica como à prática profissional. Assim, abordou 
problemas relativos à comunicação efetiva de conhecimento, bem como ao registro desses conhecimentos entre pessoas, em contextos de uso individual, social e institucional de informação e necessidades informacionais. Para tanto, a ciência da informação utilizou-se dos recursos tecnológicos disponíveis para consecução de seus objetivos (SARACEVIC, 1995).

No âmbito da prática profissional brasileira, Santa Anna e Pieri (2017) realizaram uma revisão sistemática da literatura utilizando a Base de Dados Referenciais de Artigos de Periódicos em Ciência da Informação (BRAPCI). Foram selecionados apenas os periódicos que priorizam publicações relacionadas a atividades profissionais. Os descritores empregados foram "Ciência da Informação" e "Profissional da Informação". Dessa forma, foram selecionados 31 artigos de 1996 a 2015, sendo que as principais práticas profissionais identificadas foram:

fazeres técnicos, voltados à produção, tratamento e armazenamento; ampliação do ciclo informacional, a qual se estende à questão da disseminação, do acesso e do uso da informação; práticas de comunicabilidade, interatividade e recuperação da informação; práticas de gestão da informação e seus fluxos; trabalho interdisciplinar em meio à atuação autônoma, inovadora e audaciosa; ações a favor do usuário, conhecendo seu perfil, necessidades, limitações e seu comportamento; prestação de atendimento personalizado e qualificado; e, por fim, ações de inclusão social, por meio de práticas interventivas, as quais viabilizem a construção da cidadania, desencadeando uma sociedade mais inclusiva, democrática e igualitária (SANTA ANNA, PIERI, 2017, p. 15).

A referida revisão também apontou a ciência da informação como área de conhecimento voltada ao gerenciamento da informação por meio de diferentes tecnologias. Nesse sentido, as TICs apresentam-se a serviço das práticas profissionais em ciência da informação.

Barreto (1999) já apontava que a crise e o crescimento que definiriam os rumos da ciência da informação poderiam ser comparados com as transmutações verificadas na transição da sociedade acústica para a sociedade escrita e tipográfica. Essa transição foi, de fato, tão profunda e transformadora para o indivíduo e para a sociedade como a observada na transição da sociedade escrita para a sociedade baseada nas TICs, nos moldes em que é vista atualmente.

Seguindo a linha de argumentação do autor, é possível 
destacar que a sociedade eletrônica da informação afetou, de modo incisivo, a delimitação do espaço e do tempo. A nova forma de sociedade também modificou as formas de circulação de informação. Os avanços tecnológicos forneceram a infraestrutura para o estabelecimento de um novo relacionamento da informação com seus usuários.

A redução drástica do tempo necessário para produção e disseminação de informação foi tratada por Le Coadic (1996) sob o conceito de implosão do tempo. Essa redução de tempo é causada por fatores como o aumento das taxas de processamento de dados pelos computadores e a superação quase instantânea de grandes distâncias pelos sistemas de telecomunicações. Associada à implosão do tempo, o autor também menciona a explosão da quantidade de informação. De forma combinada, ambas geram elevados fluxos de informação, como observados na atual sociedade.

Por isso, a nova forma de sociedade é denominada sociedade da informação por alguns autores. A sociedade da informação pode ser vista como:

\begin{abstract}
um modo de desenvolvimento social e econômico, em que a aquisição, armazenamento, processamento, valorização, transmissão, distribuição e disseminação de informação desempenham um papel central na atividade econômica, na geração de novos conhecimentos, na criação de riquezas, na definição da qualidade de vida e satisfação das necessidades dos cidadãos e das suas práticas culturais (LEGEY; ALBAGLI, 2000).
\end{abstract}

Para Pinho (2011), a sociedade contemporânea é denominada sociedade da informação devido ao papel central assumido pela informação a partir das TICs. A expansão da Internet se destaca neste cenário por resultar em mudanças nas esferas sociais, econômicas, políticas, culturais e filosóficas. Trata-se, no entanto, de uma realidade em construção e muito dinâmica. Heylighen e Lenartowicz (2017) visualizam um futuro para a sociedade da informação em que toda a humanidade possa se conectar por meio das TICs, em uma rede adaptativa e autoorganizada, de modo a formar um sistema coeso.

Além disso, também merecem destaque as modificações proporcionadas pela interatividade e interconectividade no que se refere à relação da informação com aqueles que farão uso dela (BARRETO, 1999). A interatividade apresenta-se como um diferencial das TICs, especialmente da Internet (ROZA, 2017). A 
interconectividade, por sua vez, é suportada pelas redes de computadores e, em nível global, pela Internet (TANENBAUM, WETHERALL, 2011), importantes recursos tecnológicos presentes na sociedade da informação.

No âmbito da sociedade da informação, as TICs apoiam o processo de construção, comunicação e uso da informação. A Figura 1 ilustra a relação entre o ciclo da informação (LE COADIC, 1996), os recursos da TIC e a sociedade da informação.

FIGURA 1 - Ciclo da informação, tecnologia e sociedade

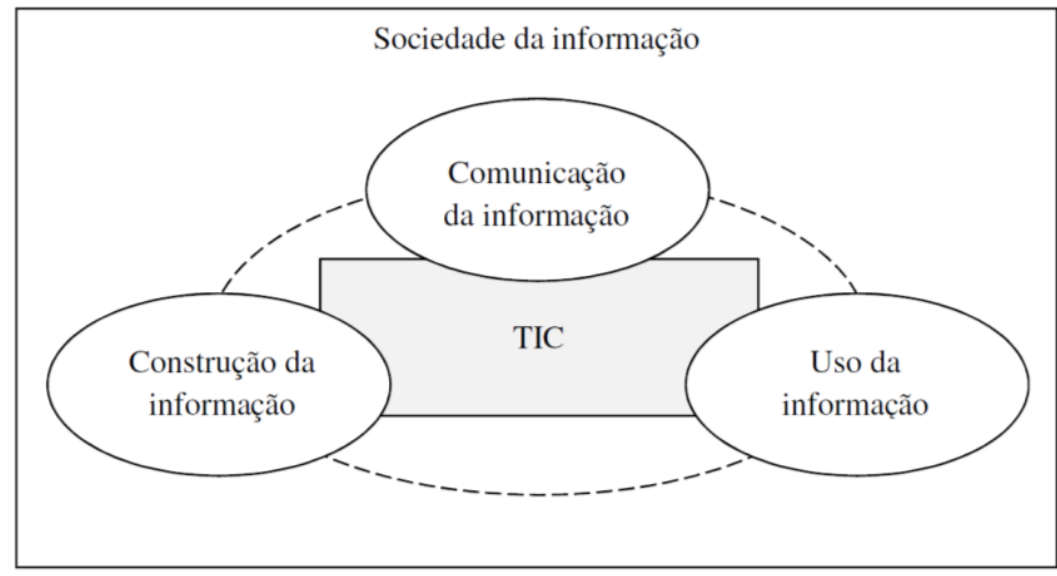

LEGENDA: - Ciclo da informação

FONTE: o autor (2017)

Barreto (1999) também já apontava que as transformações das tecnologias, com destaque ao armazenamento e à transmissão de informação, vinham modificando as relações entre a informação e seus usuários, seus intermediários e com a pesquisa no campo da ciência da informação. As instabilidades mais notáveis, segundo o autor, são: mudanças na estrutura da informação, mudanças no fluxo da informação e os efeitos sofridos por ambas como consequência da globalização.

No primeiro caso, embora as bases das estruturas da informação permaneçam sendo o código linguístico comum, como elemento obrigatório e sistemático no âmbito de uma comunidade linguística, ou de informação, a mensagem se mostra cada vez mais direcionada a cada indivíduo. Ela tem um novo formato, incluindo som e imagem, na composição de novas linguagens. É o que se 
verifica, por exemplo, do hipertexto, que permite ao indivíduo estabelecer seu próprio critério de relevância no acesso à informação e uso dela.

No caso da mudança do fluxo de informação, os recursos tecnológicos buscam permitir um acesso mais amplo e melhor à informação, aproximando os estoques de informação de seus usuários. Essa é uma perspectiva típica da ciência da computação. A ciência da informação, por outro lado, tem foco na qualificação desse acesso, considerando as competências do indivíduo para que a assimilação da informação ocorra de fato. Observa-se, neste ponto, uma clara relação interdisciplinar ente ciência da informação e ciência da computação (SARACEVIC, 1995), no que se refere às suas ações sobre os fluxos de informação.

Já a globalização, como um fenômeno de grande amplitude, afeta tanto as estrutura como os fluxos de informação. Resulta em novas perspectivas de informação, mas também vincula uma parcela grande dos estoques de informação a territórios estrangeiros. Difunde a linguagem das estruturas da informação entre as nações e também importa novas manifestações culturais advindas de outras regiões por meio dos fluxos de informações. Evidentemente, todas essas consequências podem ser desejáveis ou não, à medida que podem trazer vantagens ou desvantagens para seus interlocutores.

Por fim, conforme apontado por Barreto (1999), cabe salientar que o computador e sua forma de processar texto foram considerados contra a linguagem natural e, por conseguinte, contra a própria comunicação humana. Em função do modo como lida com a linguagem, o computador foi considerado, durante muito tempo, culpado pala redução semiótica. Para o autor, contudo, os maiores entraves ao fluxo de informação advêm do ocultamento intencional da informação através da reformatação do seu conteúdo, utilizandose de metalinguagem, metaconhecimento ou referenciais semânticos privados.

Além disso, os avanços tecnológicos, em campos como machine learning (SAMUEL, 2000) e deep learning (LECUN; BENGIO; HINTON, 2015), por exemplo, têm trazido novas perspectivas para o tratamento da informação, permitindo maior aproximação da "linguagem" das máquinas com a linguagem e comunicação humana. Nesse sentido, a ciência da informação passa a contar com novos recursos das TICs para consecução dos seus objetivos, contribuindo, de modo cada vez mais efetivo, para os avanços da sociedade da informação. 


\section{CONSIDERAÇÕES FINAIS}

A ciência da informação distingue-se de outras disciplinas no campo da informação, por se dedicar ao estudo das propriedades gerais da informação. Volta-se, em linhas gerais, à análise dos processos de construção, comunicação e uso da informação e também à concepção de produtos e serviços direcionados a esses processos e ao armazenamento da informação.

A construção, a comunicação e o uso da informação se realimentam reciprocamente, compondo o ciclo da informação. Representam, desse modo, o modelo social da informação. Esse modelo difere-se do modelo de comunicação em massa, bem como do modelo da teoria da informação, por sua dimensão humana e social.

A interdisciplinaridade é outra característica marcante da ciência da informação. No âmbito dos interesses do presente estudo, dentre as várias áreas que estabelecem uma relação interdisciplinar com a ciência da informação, é possível destacar a ciência da computação, bem como outras áreas correlatas como a informática, a eletrônica e as telecomunicações.

Ambas as ciências, da informação e da computação, possuem diversos esforços de pesquisa e desenvolvimento em comum, embora muitas vezes desvinculados. De qualquer modo, cabe salientar que elas se complementam: a primeira voltada a questões computacionais associadas à informação; a segunda, à natureza da informação e seu uso por humanos.

Diante da atual realidade social, denominada sociedade da informação, dentre outras nomenclaturas, é muito importante compreender as questões técnicas relativas às TICs, pois tais tecnologias estão na base das próprias transformações sociais e viabilizam a implementação de várias soluções no campo da informação. Todavia, a informação só se caracteriza como tal se puder ser assimilada pelas pessoas, de modo a gerar conhecimento em nível individual e coletivo, conforme ressaltado pela ciência da informação. Assim, ao voltar seus olhares para uma realidade transformada pelas TICs, a ciência da informação fornece uma importante visão sobre as questões informacionais atuais, contribuindo, de forma determinante, para os avanços da sociedade da informação. 
Recebido em: 05 dez. 2017. Aceito em: 05 mar. 2019.

\section{REFERÊNCIAS}

BARANAUSKAS, M. C. C.; SOUZA, C. S.; PEREIRA, R. (Orgs.). (2015). I GranDIHC-BR: Grand Research Challenges in Human-Computer Interaction in Brazil. Cuiabá: Brazilian Computer Society, 2015.

BARRETO, A. A. Os destinos da ciência da informação: entre o cristal e a chama. Informação \& Sociedade. v. 9, n. 2, p. 371-382, 1999.

BEGOLI, E.; HOREY, J. Design principles for effective knowledge discovery from big data. In: Software Architecture (WICSA) and European Conference on Software Architecture (ECSA). IEEE/IFIP, 2012. p. 215-218.

CASTELLS, M. The rise of the network society: The information age: Economy, society, and culture. Oxford: Wiley-Blackwell, 2010.

DODD, A. Z. O guia essencial para telecomunicações. Rio de Janeiro: Campus, 2000.

FALSARELLA, O. M.; JANNUZZI, C. A. S. C.; SUGAHARA, C. R. Gestão estratégica empresarial: proposição de um modelo de monitoramento informacional na era do big data. RDBCl: Revista Digital de Biblioteconomia e Ciência da Informação, v. 15, n. 2, p. 420-441, 2017.

HEWETT, T. T. el al. ACM SIGCHI curricula for human-computer interaction. New York: Association for Computing Machinery, 1992.

HEYLIGHEN, F.; LENARTOWICZ, M. The Global Brain as a model of the future information society: An introduction to the special issue. Technological Forecasting \& Social Change, 2017.

LE COADIC, Y. F. A ciência da informação. Brasília: Briquet de Lemos Livros, 1996.

LECUN, Y.; BENGIO, Y.; HINTON, G. Deep learning. Nature, v. 521, n. 7553, p. 436-444, 2015.

LEGEY, L.; ALBAGLI, S. Construindo a sociedade da informação no Brasil: uma nova agenda. DataGramaZero - Revista de Ciência da Informação, v. 1, n. 5, 2000.

LEINER, Barry M. et al. A brief history of the Internet. ACM SIGCOMM Computer Communication Review, v. 39, n. 5, p. 22-31, 2009.

PINHO, J. A. G. Sociedade da informação, capitalismo e sociedade civil: reflexões sobre política, internet e democracia na realidade brasileira. Revista de Administração de empresas, v. 51, n. 1, p. 98-106, 2011.

PRESSMAN, R. S. Engenharia de software: uma abordagem profissional. Porto Alegre: McGraw Hill Brasil, 2011. 
REZENDE, D. A. Engenharia de software e sistemas de informação. Rio de Janeiro: Brasport, 2005.

$\mathrm{ROZA}, \mathrm{R} \mathrm{H}$. Estilos de aprendizagem e o uso das tecnologias da informação e comunicação. 2017. 157p. Tese (Doutorado em Psicologia como Profissão e Ciência) - Pontifícia Universidade Católica de Campinas, Centro de Ciências da Vida, Programa de Pós-Graduação em Psicologia, Campinas, 2017.

RUSSELL, S.; NORVIG, P. Inteligência Artificial. Rio de Janeiro: Campus, 2013.

SAMUEL, A. L. Some studies in machine learning using the game of checkers. IBM Journal of research and development, v. 44, n. 1.2, p. 206226, 2000.

SANTA ANNA, J.; PIERI, E. M. M. Práticas profissionais em ciência da informação: uma revisão da literatura. Biblionline, v. 13, n. 1, p. 51-70, 2017.

SARACEVIC, T. Interdisciplinary nature of information science. Ciência da Informação, Brasília, v. 24, n. 1, p. 36-41, 1995.

SHANNON, C. E. A mathematical theory of communication. Bell System Technical Journal, v. 27, p. 379-423, 1948.

SHANNON, C. E.; WEAVER, W. A teoria matemática da comunicação. São Paulo: Difel, 1975.

SOARES, L. F. G.; LEMOS, G.; COLCHER, S. Redes de computadores: das LANs, MANs e WANs às redes ATM. Rio de Janeiro: Editora Campus, 1995.

STEVENSON COMMITTEE et al. Information and communications technology in UK schools: An independent enquiry (The Stevenson Report). 1997.

TAKAHASHI, Tadao (Org.). Sociedade da informação no Brasil: livro verde. Ministério da Ciência e Tecnologia, 2000.

TANENBAUM, A. S. Modern operating systems. London: Pearson Education, 2009.

TANENBAUM, A. S.; WETHERALL, D. J. Computer Networks, 5th Edition. Boston: Prentice Hall. 2011.

WALDMAN, H.; YACOUB, M. D. Telecomunicações: princípios e tendências. São Paulo: Érica, 1997. 